OPEN ACCESS

Edited by:

Carlos Chastre,

Faculty of Sciences and Technology,

New University of Lisbon, Portugal

Reviewed by:

Pavel Lukac,

Charles University, Czechia Ferdinand Dobeš, Institute of Physics of Materials

(ASCR), Czechia

*Correspondence:

Hajo Dieringa

hajo.dieringa@hzg.de

Specialty section:

This article was submitted to

Structural Materials,

a section of the journal

Frontiers in Materials

Received: 24 April 2019 Accepted: 07 October 2019 Published: 23 October 2019

Citation:

Gavras S, Zhu S, Easton MA, Gibson MA and Dieringa H (2019)

Compressive Creep Behavior of

High-Pressure Die-Cast

Aluminum-Containing Magnesium

Alloys Developed for Elevated

Temperature Applications.

Front. Mater. 6:262.

doi: 10.3389/fmats.2019.00262

\section{Compressive Creep Behavior of High-Pressure Die-Cast Aluminum-Containing Magnesium Alloys Developed for Elevated Temperature Applications}

\author{
Sarkis Gavras ${ }^{1}$, Suming Zhu ${ }^{2}$, Mark A. Easton ${ }^{2}$, Mark A. Gibson ${ }^{3}$ and Hajo Dieringa ${ }^{1 *}$ \\ ${ }^{1}$ MaglC - Magnesium Innovation Centre, Institute of Materials Science, Helmholtz-Zentrum Geesthacht, Geesthacht, \\ Germany, ${ }^{2}$ School of Engineering, RMIT University, Melbourne, VIC, Australia, ${ }^{3}$ CSIRO Manufacturing, Clayton, VIC, Australia
}

In addition to AZ- and AM-series magnesium alloys, which are mainly used at ambient temperature, there are also die-cast magnesium alloys developed for use at elevated temperatures. This paper examines the compressive creep resistance of several aluminum-containing magnesium high-pressure die-cast alloys, including the commercially available AE42, AE44-2, AE44-4, MRI230D alloys and newly developed DieMag series, i.e., DieMag211, DieMag422, and DieMag633. Compressive creep is the common load case for automotive powertrain components such as transmission housings, engine blocks or oil pans, which are typically mounted with steel or aluminum bolts that have lower thermal expansion than magnesium alloys. When the components heat up, there is a compressive load in the area around the bolt. The compressive creep experiments are accompanied by microstructure investigations. It is shown that MRI230D and the two high-concentrated DieMag alloys have the best creep resistance at $200^{\circ} \mathrm{C}$. Similar results are also observed in the tensile tests at room temperature and $150^{\circ} \mathrm{C}$, with DieMag633 showing outstanding strength.

Keywords: magnesium alloys, creep, high-pressure die casting, microstructure, density

\section{INTRODUCTION}

Magnesium alloys are predominantly cast (Avedesian and Baker, 1999). Only a small proportion of the alloys used are formed, e.g., rolled, extruded, or forged. The proportion of magnesium processed in high-pressure die casting (HPDC) is also comparably high compared to other casting processes such as sand-casting or gravity die casting. Magnesium high-pressure die casting alloys therefore account by far for the largest proportion of magnesium materials used. This market is divided between the common room temperature alloys AZ91 and AM50/60 and the creep-resistant alloys that can be used at higher temperatures. With very few exceptions, these alloys contain aluminum as an alloying element to assist with castability. The temperature difference between liquidus and solidus temperatures, and thus the melting range of the aluminum-containing alloys is large, which enables subsequent feeding during HPDC despite the rapid cooling. The disadvantage of an aluminum content of $3-10 \%$ is the formation of the $\beta$-phase $\mathrm{Mg}_{17} \mathrm{Al}_{12}$ during solidification. It has a melting point of only $437^{\circ} \mathrm{C}$ and is therefore responsible for the poor creep resistance of AZ and AM alloys. Since the aluminum is needed 
during casting, but the $\beta$-phase hinders the creep resistance, strategies have been developed to bind the aluminum in intermetallic phases with the help of further alloying elements. These phases should have the highest possible melting points and fine distribution to increase the strength of the alloys (Pekguleryuz and Celikin, 2010). For example, rare earths (AE alloys; Powell et al., 2002; Moreno et al., 2003; Kielbus and Rzychon, 2010; Zhu et al., 2012), silicon (AS alloys; Dargusch et al., 2004; Zhang, 2005; Zhu et al., 2013), strontium (AJ alloys; Kunst et al., 2009; Kielbus and Rzychon, 2010) or calcium (AX alloys, MRI; alloys; Backes et al., 2009; Xu et al., 2009; Jiang et al., 2015) are used.

Some of the creep resistant alloys investigated in this paper are die cast specimens previously investigated by Zhu et al. (2015). The alloys are AE42, AE44-2, AE44-4, and MRI230D. Usually a misch metal consisting of $\mathrm{Ce}, \mathrm{Nd}, \mathrm{La}$, and $\mathrm{Pr}$ is used for the addition of rare earths. The alloy AE44-4 indeed contains these four rare earths as alloying elements. For cost reasons and because of the decreased availability of $\mathrm{Nd}$, there are also variations of this alloy containing only $\mathrm{Ce}$ and La. This alloy (AE44-2) is cheaper and is also investigated in this study. These commercial alloys are compared with DieMag alloys, which have an aluminum-barium-calcium proportion of $2: 1: 1$. They differ only in the absolute content of alloying elements and were produced under the same conditions and casting parameters via HPDC (Dieringa et al., 2013).

In contrast to Zhu et al. (2015), the creep tests were not carried out under tensile stress but under compressive stress. This is the loading direction which represents the more common load case for cast light metals. Typically, gearbox housings, pump housings, motor blocks, oil pans, or similar temperature-loaded components are manufactured from the alloys investigated. These components are under compressive stress in the areas where they are bolted together. When heated to operating temperature, the magnesium undergoes expansion with a coefficient of thermal expansion (CTE) of $26-32 \times 10^{-6} \mathrm{~K}^{-1}$. The aluminum or steel screw has a large CTE $\left(\sim 20-24 \times 10^{-6} \mathrm{~K}^{-1}\right.$ or $\left.\sim 10-12 \times 10^{-6} \mathrm{~K}^{-1}\right)$ and this leads to compressive stress in the magnesium component (Cverna, 2002). In the worst case, this can result in the area under the bolt joint experiencing significant creep at an assumed high temperature of $200^{\circ} \mathrm{C}$. Additionally, after cooling to room temperature, which is associated with the same greater thermal contraction, the tightness of an oil pan or a gear part is reduced. In this paper the compressive creep resistance of all alloys at $200^{\circ} \mathrm{C}$ and different stresses between 60 and $100 \mathrm{MPa}$ shall be investigated. These are approximately the maximum temperatures and stresses that outer areas of an engine block must withstand under a bolt load. The determination of the minimum creep rate and threshold stress with which a true stress exponent can be calculated allows for the combination of experimental creep tests with physical metallurgical models to describe the rate-determining deformation mechanisms during creep. The creep tests are accompanied by optical and electron microscopy in combination with an investigation of intermetallic phases to elucidate the mechanism of deformation.
TABLE 1 | Chemical compositions (wt.\%) of die-cast alloys in this investigation analyzed by ICP-OES or Arc Sparc OES (Dieringa et al., 2013; Zhu et al., 2015).

\begin{tabular}{lcccccccccc}
\hline Alloy & Al & Ba & Ca & Sr & Sn & Mn & Ce & La & Nd & Pr \\
\hline AE42 & 3.45 & - & - & - & - & 0.31 & 1.45 & 0.60 & 0.41 & 0.1 \\
AE44-2 & 3.95 & - & - & - & - & 0.15 & 2.82 & 1.32 & - & - \\
AE44-4 & 3.73 & - & - & - & - & 0.30 & 2.47 & 1.21 & 0.51 & 0.1 \\
MRI230D & 6.49 & - & 2.00 & 0.43 & 0.95 & 0.28 & - & - & - & - \\
DieMag211 & 2.01 & 1.01 & 0.97 & - & - & - & - & - & - & - \\
DieMag422 & 4.05 & 1.82 & 1.79 & - & - & - & - & - & - & - \\
DieMag633 & 6.54 & 2.76 & 2.71 & - & - & - & - & - & - & - \\
\hline
\end{tabular}

\section{MATERIALS AND METHODS}

The magnesium alloys AE42, AE44-2, AE44-4, and MRI230D are commercially available. The DieMag alloys were made of pure magnesium, aluminum, barium, and calcium and were then diecast. The composition of the alloys measured with ICP-OES or Arc Spark OES is summarized in Table 1. Specimen material was cast from the individual alloys in a 250 ton TOSHIBA cold chamber die casting machine. During the melting process and the holding time during casting, the molten surface was covered with HFC-134a inert gas in a $\mathrm{CO}_{2}$ carrier gas. None of the alloys showed burning on the surface.

The castings consist of three cavities containing two "dumbbell" and one flat test sample, the dimensions of these castings are given by Easton et al. (2008). From the dumb-bell samples, cylinders with a diameter of $6 \mathrm{~mm}$ and a length of $15 \mathrm{~mm}$ for compressive creep testing were produced by electric discharge machining. The compressive creep tests were performed at a constant temperature of $200^{\circ} \mathrm{C}$ and constant stresses of $60,70,80$, 90, and $100 \mathrm{MPa}$ using an ATS Lever Arm Creep Machine. The dumbbell specimens were tested at room temperature and $150^{\circ} \mathrm{C}$ in tensile tests. A screw-driven Instron 4505 with a $100 \mathrm{kN}$ load cell was used for the tests. A cross-head speed of $5 \mathrm{~mm} / \mathrm{min}$ and an extensometer with a measuring length of $25 \mathrm{~mm}$ were applied. Four tests were carried out for each alloy.

Density measurements according to the Archimedean principle were carried out on all alloys before and after the creep testing using a Sartorius laboratory balance, in which the sample was weighed in air and ethanol. Creep samples were used for the density measurement, both in as-cast condition and after the creep tests. At least eight samples of each alloy were tested.

Optical micrographs for grain size measurement were taken from 3 regions near the centre of each alloy to obtain the average grain sizes. A Leica DM LM optical microscope was used to capture these regions. The grain sizes were measured using the line intercept method on AnalysisPro software. Further investigation of alloy microstructures where performed on a TESCAN Vega3 SEM equipped with an EDXS detector.

\section{RESULTS AND DISCUSSION}

\section{Density}

The average densities of the alloys in the as-cast condition and after creep testing are shown in Table 2. The first column 
TABLE 2 | Densities of as-cast and crept materials and grain size measurements of as-cast alloys.

\begin{tabular}{|c|c|c|c|c|c|c|}
\hline \multirow[t]{2}{*}{ Alloy } & \multirow{2}{*}{$\begin{array}{c}\begin{array}{c}\text { Gravity } \\
\text { cast }\end{array} \\
\text { Density } \\
{\left[\mathrm{g} / \mathrm{cm}^{3}\right]}\end{array}$} & \multicolumn{3}{|c|}{ As-cast samples } & \multicolumn{2}{|c|}{ Crept samples } \\
\hline & & $\begin{array}{l}\text { Density } \\
{\left[\mathrm{g} / \mathrm{cm}^{3}\right]}\end{array}$ & $\begin{array}{c}\text { Porosity } \\
\text { [\%] }\end{array}$ & $\begin{array}{l}\text { Grain Size } \\
{[\mu \mathrm{m}]}\end{array}$ & $\begin{array}{l}\text { Density } \\
{\left[\mathrm{g} / \mathrm{cm}^{3}\right]}\end{array}$ & $\begin{array}{c}\text { Porosity } \\
\text { [\%] }\end{array}$ \\
\hline AE42 & 1.797 & $1.746 \pm 0.062$ & 2.84 & $16.4( \pm 2.1)$ & $1.763 \pm 0.0264$ & 1.89 \\
\hline AE44-2 & 1.831 & $1.776 \pm 0.0611$ & 3.00 & $16.8( \pm 1.7)$ & $1.803 \pm 0.0084$ & 1.53 \\
\hline MRI230D & 1.809 & $1.745 \pm 0.0516$ & 3.54 & $15.5( \pm 0.7)$ & $1.775 \pm 0.0259$ & 1.88 \\
\hline Diemag211 & 1.803 & $1.770 \pm 0.0299$ & 1.83 & $23.7( \pm 2.9)$ & $1.759 \pm 0.0187$ & 2.44 \\
\hline DieMag422 & 1.815 & $1.763 \pm 0.0154$ & 2.86 & $24.5( \pm 1.7)$ & $1.764 \pm 0.0131$ & 2.81 \\
\hline DieMag633 & 1.819 & $1.792 \pm 0.0122$ & 1.48 & $13.7( \pm 0.3)$ & $1.801 \pm 0.0028$ & 0.99 \\
\hline
\end{tabular}

TABLE 3 | Tensile properties at RT and $150^{\circ} \mathrm{C}$.

\begin{tabular}{|c|c|c|c|c|c|c|}
\hline \multirow[t]{2}{*}{ Alloy } & \multicolumn{3}{|c|}{ RT } & \multicolumn{3}{|c|}{$150^{\circ} \mathrm{C}$} \\
\hline & $\begin{array}{c}0.2 \% \text { proof } \\
\text { [MPa] }\end{array}$ & $\begin{array}{c}\text { UTS } \\
\text { [MPa] }\end{array}$ & $\begin{array}{c}\text { Elongation } \\
{[\%]}\end{array}$ & $\begin{array}{c}0.2 \% \text { proof } \\
\text { [MPa] }\end{array}$ & $\begin{array}{c}\text { UTS } \\
\text { [MPa] }\end{array}$ & $\begin{array}{c}\text { Elongation } \\
\text { [\%] }\end{array}$ \\
\hline AE42 & $121.6 \pm 4.7$ & $238.4 \pm 10.8$ & $11.8 \pm 4.1$ & $95.0 \pm 1.8$ & $130.2 \pm 2.2$ & $31.1 \pm 2.0$ \\
\hline AE44-2 & $127.4 \pm 3.4$ & $256.6 \pm 1.5$ & $14.2 \pm 1.1$ & $101.0 \pm 1.5$ & $151.8 \pm 0.8$ & $43.6 \pm 7.1$ \\
\hline AE44-4 & $129.6 \pm 3.1$ & $251.8 \pm 3.7$ & $13.2 \pm 1.7$ & $105.0 \pm 2.4$ & $152.8 \pm 1.5$ & $31.8 \pm 2.8$ \\
\hline MRI230D & $179.7 \pm 2.9$ & $220.9 \pm 8.8$ & $4.1 \pm 0.9$ & $140.2 \pm 3.3$ & $181.4 \pm 5.2$ & $6.3 \pm 1.2$ \\
\hline DieMag211 & $140.6 \pm 2.3$ & $165.9 \pm 14.6$ & $2.5 \pm 1.8$ & $111.5 \pm 5.2$ & $144.0 \pm 7.1$ & $6.8 \pm 2.1$ \\
\hline DieMag422 & $172.6 \pm 4.5$ & $196.9 \pm 6.5$ & $1.4 \pm 0.4$ & $142.6 \pm 1.2$ & $182.1 \pm 3.5$ & $7.6 \pm 1.6$ \\
\hline DieMag633 & $202.6 \pm 0.7$ & $229.6 \pm 5.8$ & $1.6 \pm 0.5$ & $160.0 \pm 1.5$ & $196.1 \pm 2.9$ & $3.2 \pm 0.7$ \\
\hline
\end{tabular}

contains density measurements from gravity castings for the respective alloys. These values are used for comparison to the density of the same alloys produced via HPDC. The density of the gravity casting samples can be regarded as a pore-free microstructure, since a laminar flow of the melt does not cause any gas inclusions and the solidification was performed without stress. We calculate the porosity as the relative difference of the densities of the materials compared to gravity casting. MRI230D shows the highest porosity with 3.5\%. The AE-based alloys follow with 2.4 to $3.0 \%$. Only DieMag211 and DieMag633 achieve porosities of $<2 \%$ with the lowest value of $1.5 \%$ for DieMag633, which is a very low percentage for high-pressure die casting. The same is true for the densities of the crept samples. The pores are compressed during creep, which reduces porosity. It should be noted that DieMag633 stands out with a porosity of only $1 \%$, which is of course also due to the lowest value in the as-cast state.

\section{Tensile Tests}

Tensile tests at room temperature and $150^{\circ} \mathrm{C}$ show a broad range of mechanical performance for the various alloys, as summarized in Table 3. At room temperature, the AE42 has the lowest yield strength with only 121.6 MPa, but good tensile strength with almost $240 \mathrm{MPa}$. The two AE44 variants are slightly higher for both values and differ only slightly to each other, but show the best ductility of all the alloys tested. With almost $180 \mathrm{MPa}$, the MRI230D has a significantly higher yield strength, but does not show much further strain hardening up to a tensile strength of $220.9 \mathrm{MPa}$ and moderate ductility. The three DieMag alloys show an increasing strength with increasing content of alloying elements. DieMag422 has similar properties to MRI230D, but DieMag633 which has a yield strength of more than $200 \mathrm{MPa}$ exhibits excellent properties, but at the expense of ductility.

At $150^{\circ} \mathrm{C}, \mathrm{AE} 42$ again shows the lowest strength, followed by the two AE44 alloys. The MRI230D is significantly better with a yield strength of $140.2 \mathrm{MPa}$ and a ductility of $6.3 \%$. Again, DieMag422 is in the range of MRI230D and slightly exceeds it. With a yield strength of $160 \mathrm{MPa}$ and a tensile strength of almost $200 \mathrm{MPa}$, DieMag633 shows the best properties, again at the expense of ductility of only $3.2 \%$.

\section{Compressive Creep}

Creep curves of compressive creep tests at $200^{\circ} \mathrm{C}$ and $60,70,80$, 90, and $100 \mathrm{MPa}$ are shown in Figures 1A-E. Figures 1F-J shows the creep rates from Figures $\mathbf{1 A - E}$, the creep strain curves. All figures show that the AE42 always has the fastest deformation rate and thus the worst creep properties. The slowest deformation 

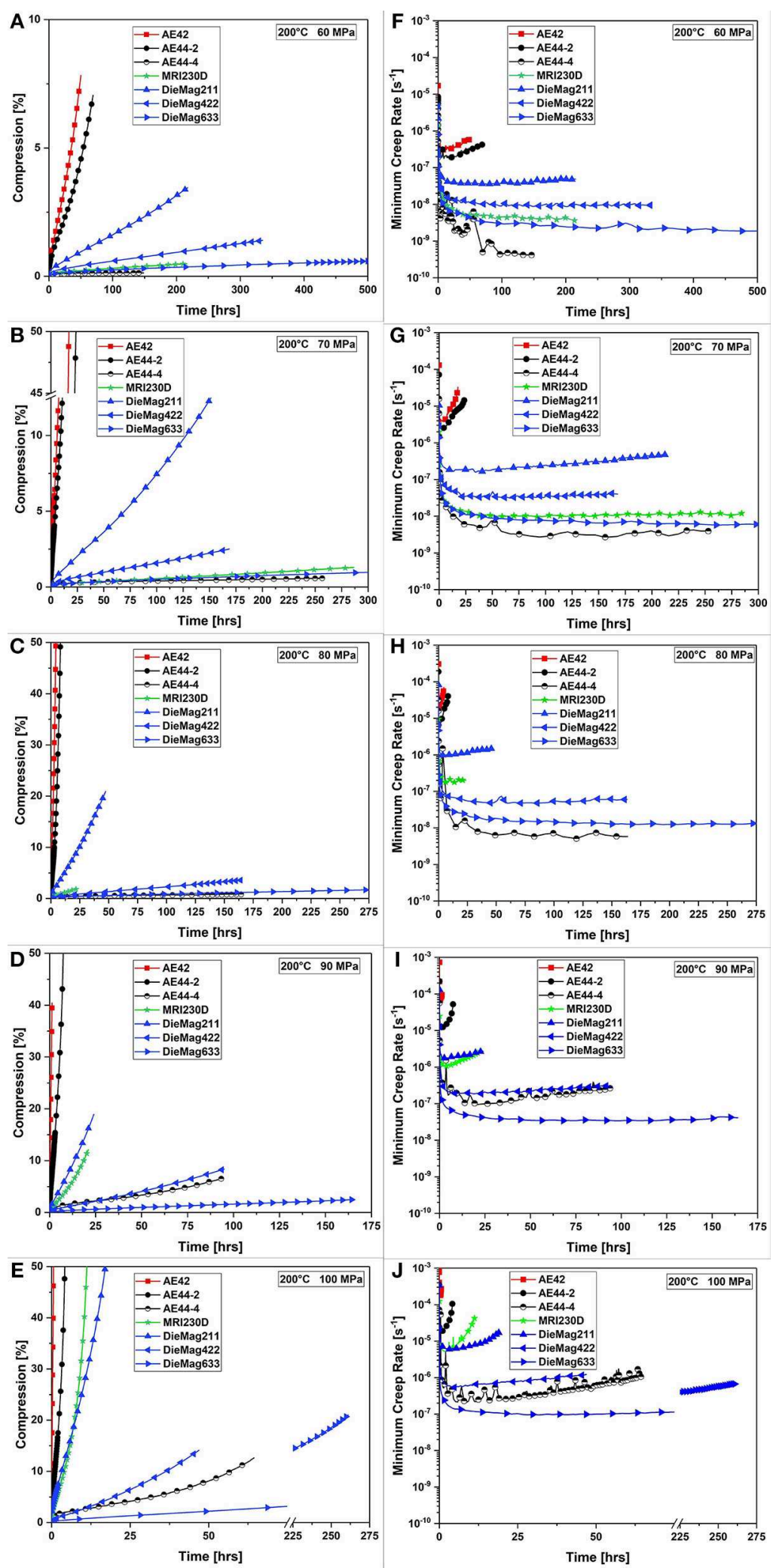

FIGURE 1 | Creep strain curves (A-E) and creep rate curves (F-J) of creep tests at $200^{\circ} \mathrm{C}$ and $60-100$ MPa applied stress. 
is shown by the AE44-4 at low stresses and the DieMag633 at higher stresses.

Equation (1) describes the dependence of the minimum creep rate on the temperature $(473.15 \mathrm{~K})$, and the applied stress $(60-$ $100 \mathrm{MPa})$.

$$
\dot{\varepsilon}_{s}=\frac{A D G b}{k T}\left(\frac{\sigma}{G}\right)^{n}
$$

In Equation (1), $A$ is a material dependent constant, $b$ is the Burgers vector, $G$ is the shear modulus, $k$ is the Boltzmann constant, and $D$ is the diffusion coefficient for which Equation (2) applies.

$$
D=D_{0} e^{\frac{-Q_{C}}{R T}}
$$

In Equation (2), $D_{0}$ is the frequency factor, $Q_{C}$ is the true activation energy for creep, and $R$ is the gas constant. From the curves in Figures 1F-J, the minimum creep rates $\dot{\varepsilon}_{s}$ are extracted and plotted according to the Norton-Arrhenius Equation (1) as plots of the minimum creep rate over the applied stress $\sigma$ at constant temperature $\mathrm{T}$ (Figure 2A). It is clear that the AE42 together with the AE44-2 has the worst creep resistance at $200^{\circ} \mathrm{C}$. They are followed by DieMag211, MRI230D, and DieMag422, which show lower minimum creep rates in this temperature range. The lowest values of the minimum creep rate and thus the best creep resistance at $200^{\circ} \mathrm{C}$ at the lower stresses of 60,70 , and $80 \mathrm{MPa}$ was found to be for AE44-4 and at the higher stresses of 90 and $100 \mathrm{MPa}$ was DieMag633.

The stress exponents are between 8 and 15 (Table 4). They appear very high according to the values expected to correlate with the rate-determining deformation mechanisms, but such high values are often reported in metal matrix composites or particle- or precipitate-strengthened alloys (Park et al., 1990; Pandey et al., 1992; Gonzalez-Doncel and Sherby, 1993). A stress exponent of $n=1$ represents diffusion-controlled creep (Harper and Dorn, 1957; Ardell and Lee, 1986), $n=3$ represents viscous gliding of dislocations (Weertman, 1957a; Sherby and Burke, 1968; Mohamed and Langdon, 1974; Mohamed et al., 1992), $n=5$ represents dislocation climbing at higher temperatures (Weertman, 1957b; Sherby and Burke, 1968; Mohamed et al., 1992) and $n=7$ represents dislocation climbing at lower temperatures (Robinson and Sherby, 1969). For these particleor precipitation-strengthened materials, a threshold stress $\sigma_{\text {thr }}$ was defined, which describes the minimum stress at which creep deformation still occurs at a certain temperature. While the existence of this threshold stress is unquestioned in literature, there are various mechanistic explanations for its origin. A common explanation of the threshold stress $\sigma_{\text {thr }}$ is the existence of an additional stress needed to bend dislocations between the obstacles, the Orowan stress (Orowan, 1954). Another explanation is to associate the threshold stress with the stress needed to disconnect a dislocation from an obstacle (Arzt and Wilkinson, 1986; Arzt and Rösler, 1988). An additional backstress for climbing over an obstacle is also considered to be the origin of the threshold stress (Arzt and Ashby, 1982).

This threshold stress can be determined by extrapolating the double-logarithmic plot of minimum creep rate over applied
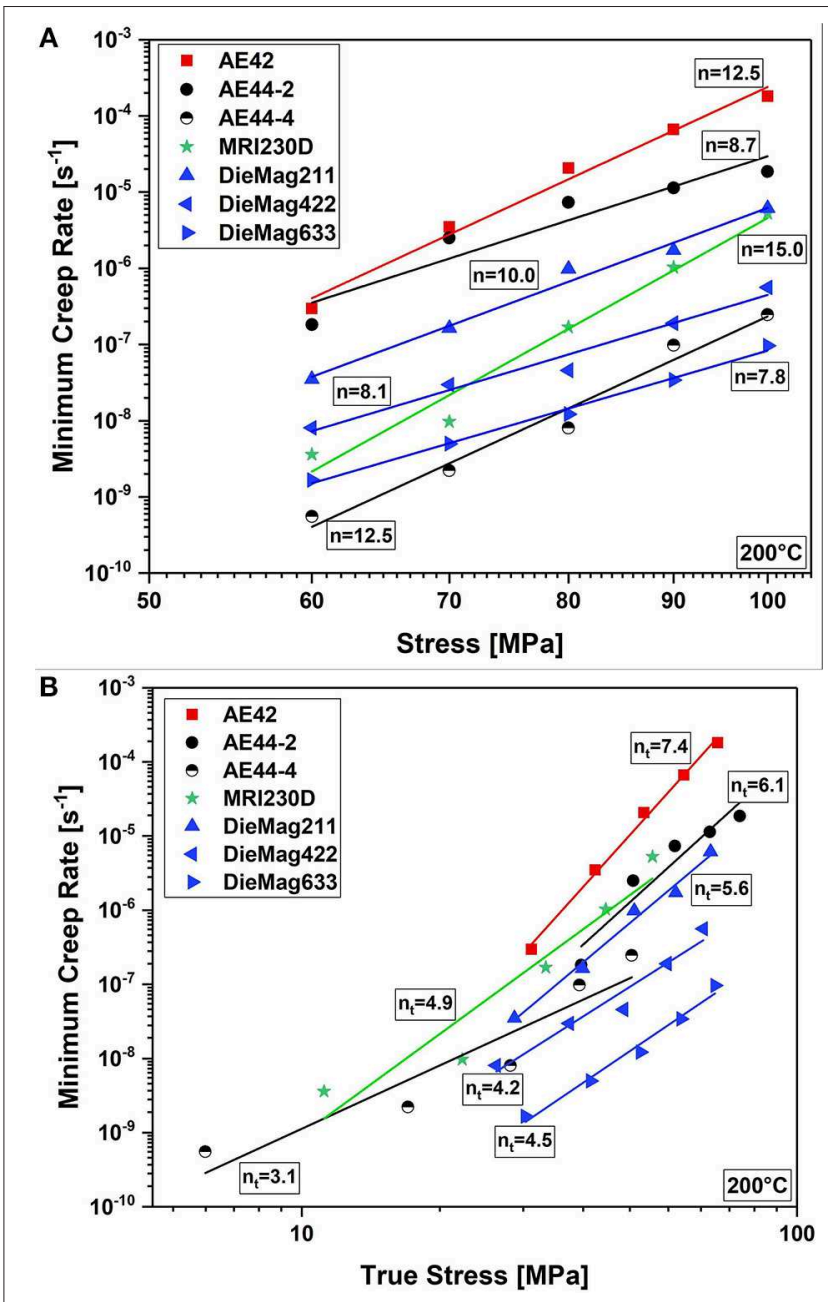

FIGURE 2 | Minimum creep rate over (A) stress applied during creep tests at $200^{\circ} \mathrm{C}$ and (B) true stress calculated with concept of threshold stresses at $200^{\circ} \mathrm{C}$.

TABLE 4 | Stress exponent $n$, threshold stress $\sigma_{t h r}$, and true stress exponent $n_{t}$ from compressive creep tests at $200^{\circ} \mathrm{C}$.

\begin{tabular}{lccc}
\hline Alloy & $\begin{array}{c}\text { Stress exponent } \\
\mathbf{n}\end{array}$ & $\begin{array}{c}\text { Threshold stress } \\
\boldsymbol{\sigma}_{\text {thr }}[\mathbf{M P a}]\end{array}$ & $\begin{array}{c}\text { True stress } \\
\text { exponent } \mathbf{n}_{\mathbf{t}}\end{array}$ \\
\hline AE42 & 12.5 & 30.9 & 7.4 \\
AE44-2 & 8.7 & 23.3 & 6.1 \\
AE44-4 & 12.5 & 53.6 & 3.1 \\
MRI230D & 15.0 & 48.9 & 4.9 \\
DieMag211 & 10.0 & 33.1 & 5.6 \\
DieMag422 & 8.1 & 35.3 & 4.2 \\
DieMag633 & 7.8 & 31.7 & 4.5 \\
\hline
\end{tabular}

stress (Figure 2A). According to a method described by Li and Langdon (1997), the stress is extrapolated to a creep rate of $10^{-10} \mathrm{~s}^{-1}$, which corresponds almost to a zero deformation (1\% deformation in 3 years) and represents approximately the lowest 
A

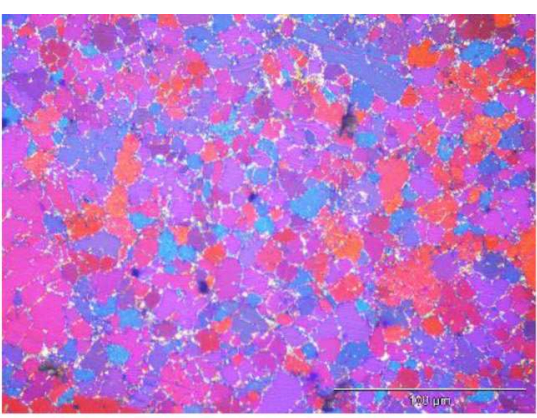

B

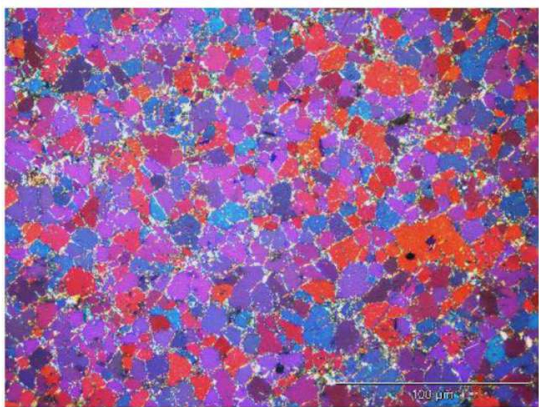

C

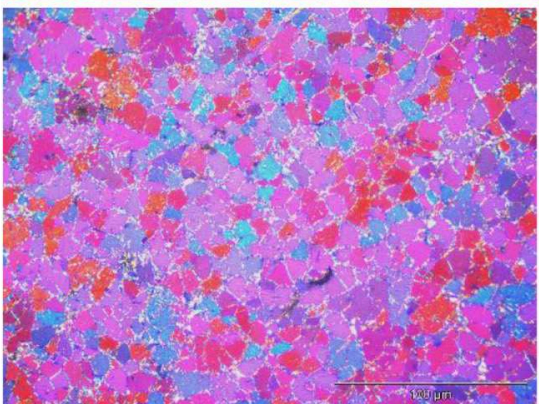

D

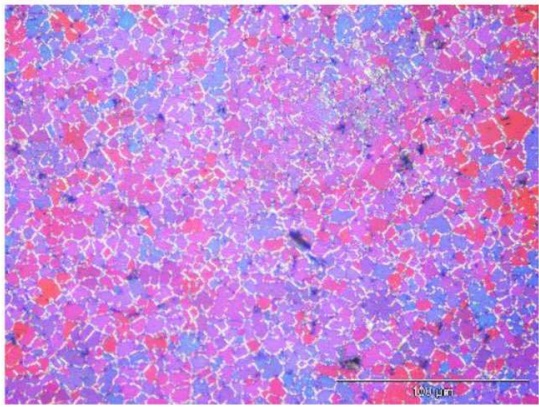

E

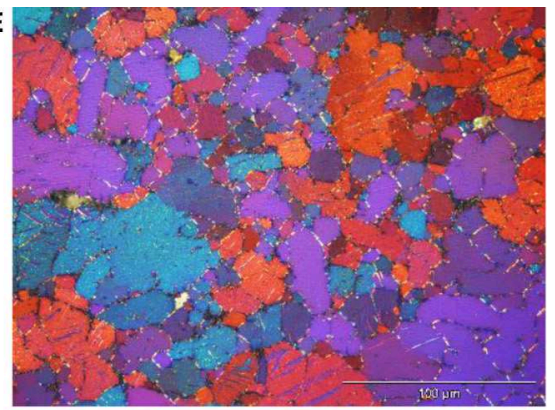

$\mathbf{F}$

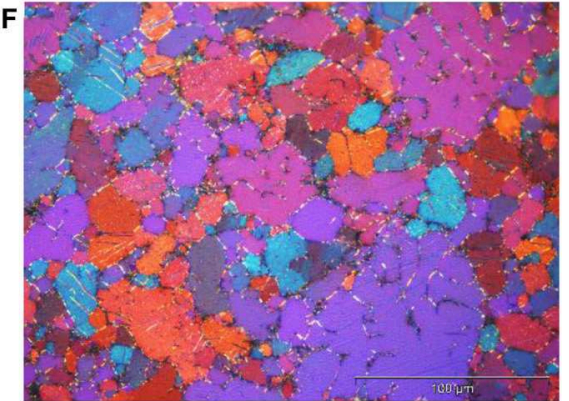

G

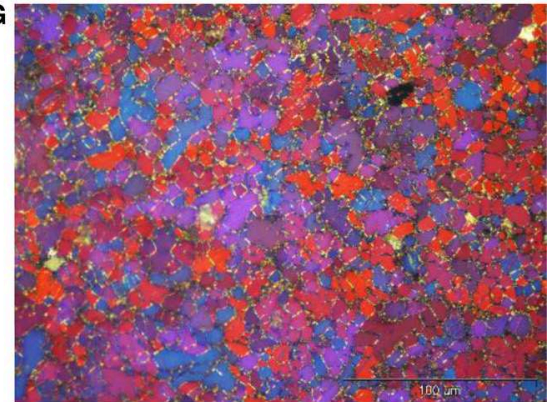

FIGURE 3 | (A-G) Micrographs of as-cast AE42, AE44-2, AE44-4, MRI230D, DieMag211, DieMag422, and DieMag633.

deformation that can be measured in creep tests. This value is the threshold stress $\sigma_{\text {thr }}$ listed in Table 4 for all alloys. With the introduction of the threshold stress, Equation (1) changes to that shown in (3):

$$
\dot{\varepsilon}_{s}=\frac{A D G b}{k T}\left(\frac{\sigma-\sigma_{t h r}}{G}\right)^{n}
$$

If the true stress exponents $\mathrm{n}_{\mathrm{t}}$ are calculated, as shown in Figure 2B, values between 3.1 and 7.4 are obtained, which is consistent with the rate determining deformation mechanisms during creep deformation. True stress exponents are listed in Table 4, as well. A stress exponent of 3.1 for the AE44-4 shows that dislocation gliding is the rate determining deformation mechanism for creep deformation at $200^{\circ} \mathrm{C}$. Higher values, as seen in DieMag alloys and the MRI230D, indicate a transition to a higher proportion of dislocation climbing in combination with dislocation glide as the deformation mechanism. For the AE42 and AE44-2, with a stress exponent of 6.1 and 7.4, only dislocation climbing can be determined as the rate determining deformation mechanism.

\section{Microstructure Analysis}

The microstructures of the seven die cast alloys are shown in Figure 3. The optical micrographs in Figure 3 are representative 


\section{A}

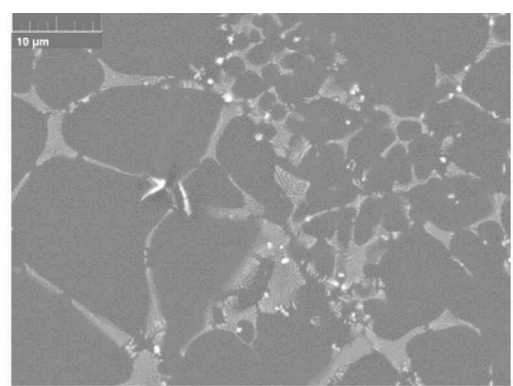

B

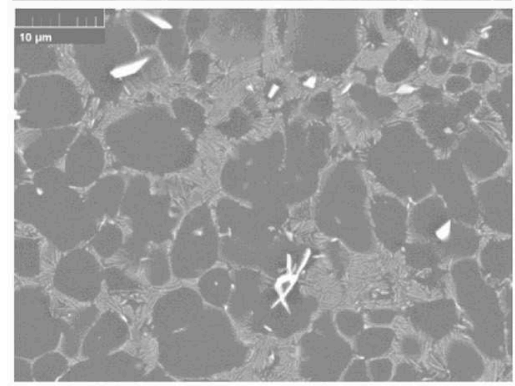

C

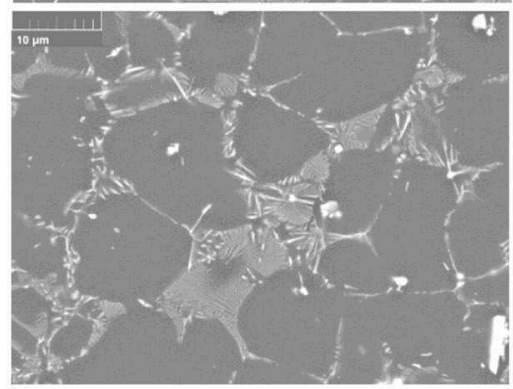

D

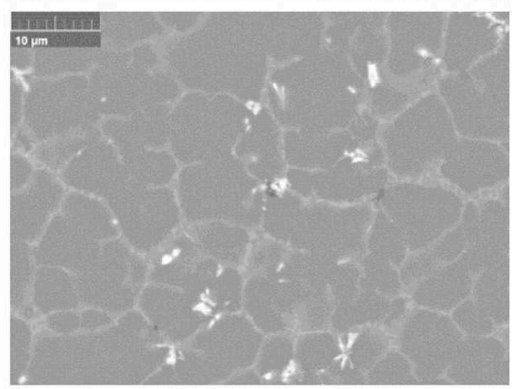

E

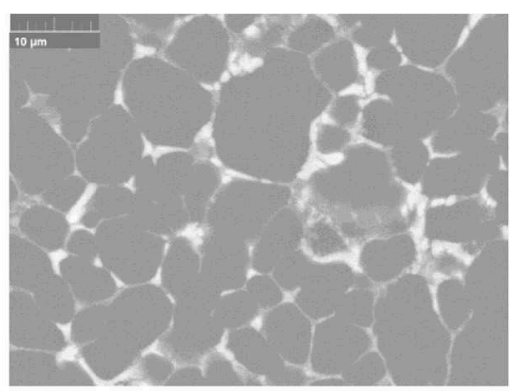

$\mathbf{F}$

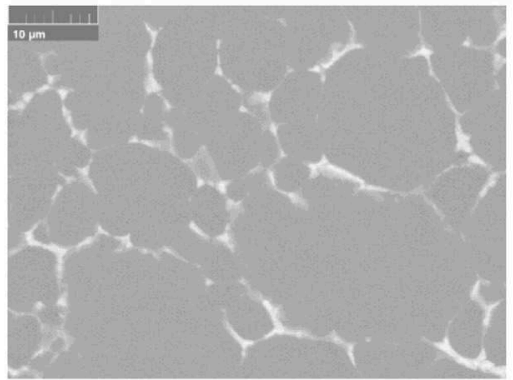

G

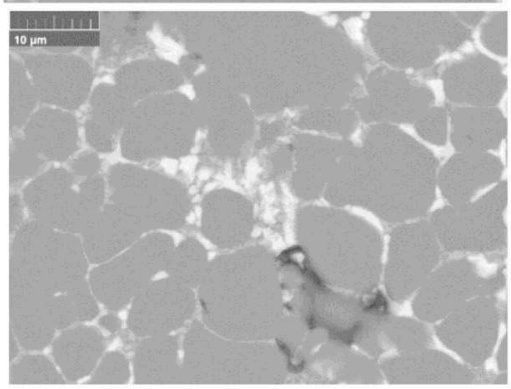

FIGURE 4 | (A-G) SEM BSE micrographs of as-cast AE42, AE44-2, AE44-4, MRI230D, DieMag211, DieMag422, and DieMag633.

of the grain morphology of each alloy. The average grain sizes are shown in Table 2.

A more detailed view of the microstructure of the newly developed DieMag alloys and those of the AE and MRI alloys under investigation is presented in Figures $4 A-D$. The variations of the $\mathrm{AE}$ alloys (Figures $4 \mathrm{~A}-\mathrm{C}$ ) all have relatively similar microstructural morphologies, a lamellar eutectic at grain boundaries and a sporadically distributed (near grain boundaries) irregularly shaped intermetallic phase. Powell et al. (2002) showed that the intermetallic phase in the eutectic was $\mathrm{Al}_{11} \mathrm{RE}_{3}$ and the irregularly shaped phase was $\mathrm{Al}_{2} \mathrm{RE}$. Zhu et al. (2012) confirmed that the 2 intermetallic phases present in the AE44 alloys were also $\mathrm{Al}_{11} \mathrm{RE}_{3}$ and $\mathrm{Al}_{2} \mathrm{RE}$.
MRI230D (Figure 4D) has a continuous intermetallic phase and a brighter (as viewed via BSE on SEM) intermetallic phase and irregularly shaped phase present at grain boundaries. The two intermetallic phases present in MRI230D have been shown to be $(\mathrm{Mg}, \mathrm{Al})_{2} \mathrm{Ca}$ and $\mathrm{CaMgSn}$ (Zhu et al., 2015). The (Mg,Al) ${ }_{2} \mathrm{Ca}$ phase, which was shown to also have, in part, a lamellar-like appearance by Luo et al. (2002), corresponds to the continuous phase in MRI230D. The brighter irregularly shaped phase was shown to be that of CaMgSn (Zhu et al., 2015).

Figures 4E-G shows a relatively consistent morphology between DieMag211, DieMag422, and DieMag633, with exception to grain size in DieMag633. For each DieMag alloy, EDXS measurements were obtained from the intermetallic 
TABLE 5 | EDXS point measurements (wt.\%) of $\mathrm{Al}_{2} \mathrm{Ca}$ or $\mathrm{Mg}_{21} \mathrm{Al}_{3} \mathrm{Ba}_{2}$ intermetallic phases in DieMag alloys.

\begin{tabular}{|c|c|c|c|c|c|c|}
\hline & \multicolumn{2}{|c|}{ DieMag211 } & \multicolumn{2}{|c|}{ DieMag422 } & \multicolumn{2}{|c|}{ DieMag633 } \\
\hline & $\mathrm{Al}_{2} \mathrm{Ca}$ & $\mathrm{Mg}_{21} \mathrm{Al}_{3} \mathrm{Ba}_{2}$ & $\mathrm{Al}_{2} \mathrm{Ca}$ & $\mathrm{Mg}_{21} \mathrm{Al}_{3} \mathrm{Ba}_{2}$ & $\mathrm{Al}_{2} \mathrm{Ca}$ & $\mathrm{Mg}_{21} \mathrm{Al}_{3} \mathrm{Ba}_{2}$ \\
\hline $\mathrm{Mg}$ & 75.7 & 68.2 & 82.5 & 72.8 & 71.8 & 63.3 \\
\hline $\mathrm{Al}$ & 12.4 & 12.3 & 8.1 & 8.6 & 15.0 & 14.7 \\
\hline $\mathrm{Ca}$ & 8.5 & 5.6 & 6.4 & 5.6 & 10.1 & 7.1 \\
\hline $\mathrm{Ba}$ & 1.6 & 12.0 & 0.9 & 10.7 & 1.4 & 12.9 \\
\hline 0 & 1.4 & 1.7 & 1.7 & 1.7 & 1.4 & 1.8 \\
\hline $\mathrm{Si}$ & 0.4 & 0.1 & 0.4 & 0.6 & 0.2 & 0.2 \\
\hline
\end{tabular}

phases present. Representative EDXS measurements of each phase in the three DieMag alloys are given in Table 5. From these measurements it can be verified that the lamellar phase has little to no $\mathrm{Ba}$, which correlates to the $\mathrm{Al}_{2} \mathrm{Ca}$ phase and the white blocky continuous phase has a significant concentration of $\mathrm{Ba}$, which indicates it is the $\mathrm{Mg}_{21} \mathrm{Al}_{3} \mathrm{Ba}_{2}$ phase. These results match the investigation by Dieringa et al. (2013), which showed that DieMag422 contained two distinct intermetallic phases, a bulk intermetallic phase with $\mathrm{Al}_{2} \mathrm{Ca}$ and a lamellar intermetallic phase with $\mathrm{Mg}_{21} \mathrm{Al}_{3} \mathrm{Ba}_{2}$.

\section{CONCLUSIONS}

The aluminum-containing, creep-resistant magnesium alloys were successfully produced by high-pressure die casting. None of the alloys showed any noticeable burning. Compressive creep tests at $200^{\circ} \mathrm{C}$, metallography, density measurements and tensile tests at RT and $150^{\circ} \mathrm{C}$ were carried out on the samples in as-cast condition. The following results were obtained:

- The density measurements can be seen as a measure for the diecastability of a magnesium alloy. DieMag211 and DieMag633 have the lowest porosities with only 1.8 and $1.5 \%$, respectively.

- The alloys with the best creep resistance, displaying the lowest minimum creep rate values at $200^{\circ} \mathrm{C}$, in combination with low stresses of 60, 70, and $80 \mathrm{MPa}$ was AE44-4 and in combination with the higher stresses of 90 and $100 \mathrm{MPa}$ was DieMag633.

\section{REFERENCES}

Ardell, A. J., and Lee, S. S. (1986). A dislocation network theory of Harper-Dorn creep I: steady state creep of monocrystalline Al. Acta Mater. 34, 2411-2423. doi: 10.1016/0001-6160(86)90144-6

Arzt, E., and Ashby, M. F. (1982). Threshold stresses in materials containing dispersed particles. Scripta Metall. 16, 1285-1290. doi: 10.1016/0036-9748(82)90484-7

Arzt, E., and Rösler, J. (1988). The kinetics of dislocation climb over hard particles-II: effects of an attractive particle-dislocation interaction. Acta Metall. 36, 1053-1060. doi: 10.1016/0001-6160(88)9 0159-9

Arzt, E., and Wilkinson, D. S. (1986). Threshold stresses for dislocation climb over hard particles: the effect of an attractive
- The mechanical properties at room temperature show varying results. With nearly $180 \mathrm{MPa}$, the commercial MRI230D had approximately the same yield strength as DieMag422, although its tensile strength is slightly lower. DieMag633 had the highest yield strength at over $200 \mathrm{MPa}$, and also the highest tensile strength. However, this is at the expense of ductility. It was remarkable to find DieMag633 had a significantly higher yield strength compared to an aluminum alloy A380, which is also used for engine components in automotive engineering. Their yield strength was approximately $165 \mathrm{MPa}$ with a ductility of 3\% (Bronfin et al., 2008).

- The mechanical properties at $150^{\circ} \mathrm{C}$ showed a similar trend. The MRI230D and DieMag422 showed comparably good properties and were only exceeded by DieMag633 with a yield strength and a tensile strength of $160 \mathrm{MPa}$ and $\sim 200$ $\mathrm{MPa}$, respectively. The yield strength was again above that of an aluminum alloy A380, which is approximately $150 \mathrm{MPa}$ (Bronfin et al., 2008).

- Microstructure as well as phase analysis of the creep-resistant magnesium alloys revealed the various intermetallic phases in the high-pressure die cast structure, which were also present in casting processes with lower cooling rates. They help to improve the creep resistance of the alloys by preferentially forming during solidification and thus avoiding the formation of the thermally unstable $\mathrm{Mg}_{17} \mathrm{Al}_{12}$, which has been shown to be detrimental to elevated temperature creep resistance.

\section{DATA AVAILABILITY STATEMENT}

The datasets generated for this study are available on request to the corresponding author.

\section{AUTHOR CONTRIBUTIONS}

SG contributed optical and electron microscopy including EDXS measurement. SZ contributed the evaluation of tensile properties. ME contributed alloy casting and coordination of authors. MG contributed alloy casting. HD contributed the density measurements, creep tests and evaluation thereof, idea of the paper, and coordination of authors.

interaction. Acta Metall. 34, 1893-1898. doi: 10.1016/0001-6160(86)9 0247-6

Avedesian, M. M., and Baker, H. (1999). ASM Specialty Handbook: Magnesium and Magnesium Alloys. Materials Park, OH: ASM International.

Backes, B., Durst, K., Amberger, D., and Göken, M. (2009). Particle hardening in creep-resistant Mg-alloy MRI 230D probed by nanoindenting atomic force microscopy. Metall. Mater. Trans. 40a, 257-261. doi: 10.1007/s11661-008-9720-1

Bronfin, B., Moscovitch, N., Trostenetsky, V., Gerzberg, G., Nagar, N., and Yehuda, R. (2008). "High performance HPDC alloys as replacements for A380 aluminum alloy," in Magnesium Technology 2008, eds M. O. Pekguleryuz, N. R. Neelameggham, R. S. Beals, and E. A. Nyberg (TMS), 411-415.

Cverna, F. (2002). ASM Handbook: Thermal Properties of Metals. Chapter 2: Thermal Expansion. Materials Park, OH: ASM International. 
Dargusch, M. S., Bowles, A., Pettersen, K., Bakke, P., and Dunlop, G. L. (2004). The effect of silicon content on the microstructure and creep behavior in die-cast magnesium AS alloys. Metall. Mater. Trans. 35A, 1905-1909. doi: 10.1007/s11661-004-0099-3

Dieringa, H., Zander, D., and Gibson, M. A. (2013). Creep behaviour under compressive stresses of calcium and barium containing $\mathrm{Mg}-\mathrm{Al}$ based die casting alloys. Mater. Sci. Forum 765, 69-73. doi: 10.4028/www.scientific.net/MSF.765.69

Easton, M., Abbott, T., Nie, J.F., and Savage, G. (2008). “An assessment of high pressure die cast Mg-Zn-Al alloys," in Magnesium Technology 2008, eds M. O. Pekguleryuz, N. R. Neelameggham, R. S. Beals, and E. A. Nyberg (Warrendale, PA: TMS), 323-328.

Gonzalez-Doncel, G., and Sherby, O. D. (1993). High temperature creep behavior of metal matrix aluminum-SiC composites. Acta Metall. Mater. 41, 2797-2805. doi: 10.1016/0956-7151(93)90094-9

Harper, J., and Dorn, J. E. (1957). Viscous creep of aluminum near its melting temperature. Acta Metall. 5, 654-665. doi: 10.1016/0001-6160(57)90112-8

Jiang, Z., Jiang, B., Yang, H., Yang, Q., Dai, J., and Pan, F. (2015). Influence of the $\mathrm{Al}_{2} \mathrm{Ca}$ phase on microstructure and mechanical properties of $\mathrm{Mg}$-Al-Ca alloys. J. Alloys Comp. 647, 357-363. doi: 10.1016/j.jallcom.2015.06.060

Kielbus, A., and Rzychon, T. (2010). Microstructure and creep properties of AJ62 and AE44 diecasting magnesium alloys. Mater. Sci. Forum 638-642, 1546-1551. doi: 10.4028/www.scientific.net/MSF.638-642.1546

Kunst, M., Fischersworring-Bunk, A., L'Esperance, G., Plamondon, P., and Glatzel, U. (2009). Microstructure and dislocation analysis after creep deformation of die-cast Mg-Al-Sr (AJ) alloy. Mat. Sci. Eng. A510-511, 387-392. doi: 10.1016/j.msea.2008.07.078

Li, Y., and Langdon, T. G. (1997). A simple procedure for estimating threshold stresses in the creep of metal matrix composites. Scripta Mater. 36, 1457-1460. doi: 10.1016/S1359-6462(97)00041-9

Luo, A., Balogh, M. P., and Powell, B. R. (2002). Creep and microstructure of magnesium-aluminum-calcium based alloys. Metall. Mat. Trans. 33A, 567-574. doi: 10.1007/s11661-002-0118-1

Mohamed, F. A., and Langdon, T. G. (1974). The transition from dislocation climb to viscous glide in creep of solid solution alloys. Acta Metall. 22, 779-788. doi: 10.1016/0001-6160(74)90088-1

Mohamed, F. A., Park, K.-T., and Lavernia, E. J. (1992). Creep behavior of discontinuous SiC-Al composites. Mater. Sci. Eng. A150, 21-35. doi: 10.1016/0921-5093(90)90004-M

Moreno, I. P., Nandy, T. K., Jones, J. W., Allison, J. E., and Pollock, T. M. (2003). Microstructural stability and creep of rare-earth containing magnesium alloys. Scripta Mater. 48, 1029-1034. doi: 10.1016/S1359-6462(02)00595-X

Orowan, E. (1954). "Dislocations and mechanical properties," in Dislocations in Metals, ed M. Cohen (New York, NY: AIME), 69-178.

Pandey, A. B., Mishra, R. S., and Mahayan, Y. R. (1992). Stady state creep behaviour of silicon carbide particulate reinforced aluminium composite. Acta Metall. Mater. 40, 2045-2052. doi: 10.1016/0956-7151(92)90190-P
Park, K. T., Lavernia, E. J., and Mohammed, F. A. (1990). High temperature creep of silicon carbide particulate reinforced aluminum. Acta Metall. Mater. 38, 2149-2159. doi: 10.1016/0956-7151(90)90082-R

Pekguleryuz, M., and Celikin, M. (2010). Creep resistance in magnesium alloys. Int. Mater. Rev. 55, 197-217. doi: 10.1179/095066010X12646898728327

Powell, B. R., Rezhets, V., Balogh, M. P., and Waldo, R. A. (2002). Microstructure and creep behavior in AE42 magnesium die-casting alloy. JOM 8, 34-38. doi: 10.1007/BF02711864

Robinson, S. L., and Sherby, O. D. (1969). Mechanical behavior of polycrystalline tungsten at elevated temperature. Acta Mater. 17, 109-125. doi: 10.1016/0001-6160(69)90132-1

Sherby, O. D., and Burke, P. M. (1968). Mechanical behavior of crystalline solids at elevated temperature. Progress Mater. Sci. 13, 325-389. doi: 10.1016/0079-6425(68)90024-8

Weertman, J. (1957a). Steady-state creep through dislocation climb. J. Appl. Phys. 28, 362-364. doi: 10.1063/1.1722747

Weertman, J. (1957b). Steady-state creep of crystals. J. Appl. Phys. 28, 1185-1189. doi: $10.1063 / 1.1722604$

Xu, S. W., Matsumoto, N., Yamamoto, K., Kamado, S., Honma, T., and Kojima, Y. (2009). High temperature tensile properties of as-cast $\mathrm{Mg}$ Al-Ca alloys. Mater. Sci. Eng. A509, 105-110. doi: 10.1016/j.msea.2009. 02.024

Zhang, P. (2005). Creep behavior of the die-cast Mg-Al alloy AS21. Scr. Mater. 52, 277-282. doi: 10.1016/j.scriptamat.2004.10.017

Zhu, S., Easton, M., Abbott, T. B., Nie, J.-F., Dargusch, M. S., Hort, N., et al. (2015). Evaluation of magnesium die casting alloys for elevated temperature applications: microstructure, tensile properties, and creep resistance. Metall. Mater. Trans. 46A, 3543-3554. doi: 10.1007/s11661-01 5-2946-9

Zhu, S. M., Easton, M. A., Gibson, M. A., Dargusch, M. S., and Nie, J. F. (2013). Analysis of the creep behaviour of die-cast $\mathrm{Mg}-3 \mathrm{Al}-1 \mathrm{Si}$ alloy. Mater. Sci. Eng. 578, 377-382. doi: 10.1016/j.msea.2013.04.100

Zhu, S. M., Nie, J. F., Gibson, M. A., Easton, M. A., and Bakke, P. (2012). Microstructure and creep behavior of high-pressure die-cast magnesium alloy AE44. Metall. Mater. Trans. 43A, 4137-4144. doi: 10.1007/s11661-012-1247-9

Conflict of Interest: The authors declare that the research was conducted in the absence of any commercial or financial relationships that could be construed as a potential conflict of interest.

Copyright (c) 2019 Gavras, Zhu, Easton, Gibson and Dieringa. This is an open-access article distributed under the terms of the Creative Commons Attribution License (CC $B Y)$. The use, distribution or reproduction in other forums is permitted, provided the original author(s) and the copyright owner(s) are credited and that the original publication in this journal is cited, in accordance with accepted academic practice. No use, distribution or reproduction is permitted which does not comply with these terms. 